\title{
Levels-of-processing effects in subject-performed tasks
}

\author{
HUBERT D. ZIMMER and JOHANNES ENGELKAMP \\ Saarland University, Saarbrücken, Germany
}

\begin{abstract}
In memory for subject-performed tasks (SPTs), subjects encode a list of simple action phrases (e.g., thumb through a book, knock at the door) by performing these actions during learning. In three experiments, we investigated the size of the levels-of-processing effects in SPTs as compared with those in standard verbal learning tasks (VTs). Subjects under SPT and VT conditions learned lists of action phrases in a surface or a conceptual orienting task. Under both encoding conditions, the subjects recalled fewer items with surface orienting tasks than with conceptual orienting tasks, but the levels-ofprocessing effects were strongly reduced in the SPT condition. In the SPT condition, items that were encoded in a surface orienting task were still substantially recalled. The items were recalled almost as well as the conceptually encoded items in the VT condition. The distinct reduction of the levels-ofprocessing effect is caused by the fact that, in SPT encoding even with a verbal surface orienting task, subjects process conceptual information in order to perform the denoted action. We attribute the small conceptual advantage, which remains with SPT despite the conceptual processing for performing, to the fact that items are not as well integrated into memory as they are when conceptual processing is focused on the action component, rather than on the semantic contexts. This lower integration reduces the accessibility of items in the verbal surface task, even with SPT encoding.
\end{abstract}

In subject-performed tasks (SPTs), subjects are given verbal commands requiring them to symbolically perform a series of minitasks-for example, cut the bread, tear the paper, paint the table, fill up the bottle. Subjects perform these actions either with real objects or with imaginary objects and, with that, attempt to memorize the actions. This is later followed by free recall or recognition of the verbal commands. In all of these studies, it was consistently observed that memory in SPTs was better than that under other study conditions, particularly those involving verbal tasks (VTs) in which subjects only listened to action phrases (for reviews, see Cohen, 1989; Engelkamp, 1998; Engelkamp \& Zimmer, 1994; Nilsson \& Bäckman, 1989). More important, it is hardly possible to improve memory for SPT. All efforts to improve SPT recall by giving instructions to elaborate upon the action concept were unsuccessful (Cohen, 1983; Engelkamp, Mohr, \& Zimmer, 1991; Helstrup, 1987; Lichty, Bressie, \& Krell, 1988; Nilsson \& Cohen, 1988; Nilsson, Nyberg, Kormi-Nouri, \& Rönnlund, 1994). This null effect of conceptual elaboration contrasts sharply with the remarkable conceptual elaboration effects consistently found with VTs (e.g., Johnson-Laird, Gibbs, \& De Mowbray, 1978).

This research was supported by a grant from the German Research Foundation (Deutsche Forschungsgemeinschaft) under En 124/13. Our thanks are due to Ute Biegelmann and Jörg Saathoff for their help in preparing and running the experiments. We are grateful to Tom Nelson, Fergus Craik, and two anonymous reviewers for their very useful comments on an earlier draft of this article. Correspondence concerning the article should be addressed to H. D. Zimmer, Saarland University, Department of Psychology, P.O. Box 151150, D-66041 Saarbrücken, Germany (e-mail: huzimmer@rz.uni-sb.de).
In VTs, memory is better after conceptual encoding than after verbal encoding (see, e.g., Craik \& Lockhart, 1972; Craik \& Tulving, 1975; Jacoby \& Craik, 1979). These studies are known as levels-of-processing studies. This result was so often replicated that the levels-of-processing effect is considered an empirical law of memory (Lockhart \& Craik, 1990). This effect is the topic of this paper, because levels-of-processing effects have seldom been investigated in SPTs, and when they have been, the results have not been consistent. We decided, therefore, to compare the size of levels-of-processing effects in SPTs with that in VTs.

The null effect of conceptual elaboration in SPTs was essentially explained by claiming that encoding by enactment is already optimal (e.g., Cohen, 1989). Leaving aside whether it is optimal or not, there are, at least, good arguments that it is always conceptual. We have postulated elsewhere that conceptual processing is always involved if a modality shift has to be done from nonverbal to verbal modality and vice versa (Engelkamp, 1991; Engelkamp \& Zimmer, 1994, p. 34). In terms of actions, this means that, in order to perform an action upon verbal command, subjects have to understand the actions they are required to perform. A similar claim was formulated for pictures by Nelson (1979).

This assumption has an important implication for a shallow, nonconceptual orienting task with an SPT. Both tasks, the verbal surface and the performing tasks, contribute to memory in SPTs, and they make available different sets of information. The surface information of the verbal phrase is processed in order to solve the nonconceptual orienting task, and in addition to this, the mean- 
ing is processed in order to perform the action. A nonconceptual orienting task, therefore, does not prevent the action concept from being encoded in an SPT. In a nonconceptual task (e.g., in a letter search task), an item is encoded as a linguistic event, and this linguistic encoding replaces the conceptual encoding of the meaning of the word. As a consequence, in a surface condition, the memory trace in a VT does not include, or only minimally includes, conceptual information. Therefore, in a VT, memory under the surface condition is worse than that under the conceptual condition. This is different in an SPT. In an SPT, conceptual information is always activated, and one should therefore not expect the decline in memory that one finds with surface encoding, as compared with conceptual encoding.

However, a further aspect must be taken into account. Conceptual encoding usually makes available relational and item-specific information. To obtain a good performance in free recall, it is necessary that subjects be provided with relational information that supports retrieval and with item-specific information that helps to recover the item (see, e.g., Hunt \& Einstein, 1981; McDaniel, Einstein, Dunay, \& Cobb, 1986). We assume that less relational information is available in the verbal surface task than in the conceptual task (cf., also, Koriat \& Melkman, 1987) and that this difference essentially contributes to the low recall level after verbal surface processing. For the size of the levels-of-processing effects in SPT, it is important that the smaller amount of relational information under surface encoding tasks, as compared with conceptual tasks, partly remains if the actions are performed. A focus on action-relevant meaning, when dealing with the to-be-performed action, provides subjects with itemspecific conceptual information, but it does not generate retrieval structures as effectively as evaluating semantic information-for example, assessing the appropriateness of a given context. Therefore, we expect that a surface orienting task lowers recall less with SPTs than with VTs, because conceptual item-specific information is processed if the actions are to be performed. However, an advantage for the conceptual orienting task remains even in SPT, because verbal surface tasks make good retrieval structures less available than does a semantic task.

Although repeated efforts have been made to improve memory in SPTs, as was mentioned, it has seldom been tested whether memory in SPTs is impaired by a surface orienting task. To the best of our knowledge, there are only two studies in which the levels-of-processing effects of VTs and SPTs were tested and compared. In a third study (Cohen, 1981), levels-of-processing effects were also investigated, but in this case, the surface processing focused on the physical features of the actions, and not on the verbal surface. This study, therefore, is not relevant here. In the first study, by Nilsson and Craik (1990), a conceptual task (indicate the frequency with which the minitask is likely to occur in a specified setting) was contrasted with a nonconceptual VT that referred to the surface structure of the action phrases (count the number of times a specified letter occurs in the command and count the number of syllables in the command). They observed the well-known levels-of-processing effect in the VT, but only a "substantially reduced" processing effect for the SPT. Thus, their findings speak in favor of a significantly reduced or no levels-of-processing effect. This result, however, contradicts a finding from Zimmer (1992), who observed a clear-cut levels-of-processing effect in both encoding conditions that was, moreover, additive to the SPT effect. Because of these conflicting results, it was the aim of the present research to investigate this relationship more systematically. In the theoretical considerations formulated above, we expected an interaction between type of encoding (SPT/VT) and level of processing (conceptual/surface). In free recall, there should be a strong levels-of-processing effect in VTs and a smaller but, nevertheless, significant levels-of-processing effect in SPTs. Moreover, in SPTs, subjects should show a substantial recall performance, even with a surface orienting task.

In addition, we expected that, in conceptual orienting tasks, the level of recall in VTs might be almost as high as that for recall in SPTs. We know that recall in VTs benefits from conceptual elaboration instructions, and we know that SPT does not benefit from additional conceptual encoding instructions. Therefore, the SPT effect might disappear with conceptual orienting tasks.

According to our theoretical considerations, we expected still another finding. We know that, with conceptual orienting tasks, items that are paired with a matching assertion (which have to be answered positively) are retained better than items that are paired with nonmatching assertions (see, e.g., Craik \& Tulving, 1975). This congruity effect is explained by assuming that matching assertions lead to an integration of the item into preexperimental memory (Hanley \& Morris, 1987). This does not happen to items with nonmatched pairings. Because of this integration, the accessibility of matched items is enhanced, and as a consequence, more matched items should be recalled than nonmatched items. We expected that performing should reduce this disadvantage of nonmatched assertions, because performing itself contributes to memory and this contribution is independent of the congruity of the assertion. We therefore expected an interaction between the congruity and the type of encoding with a conceptual orienting task. With surface encoding tasks, the variation of congruity plays a minor role. In nonconceptual tasks, the accessibility of items is generally low, because the preexisting surface knowledge is poor and, therefore, the integration is always low. Craik and Tulving (1975), for instance, did not observe an effect of congruity with surface encoding. We expected the same result in our experiments. The congruity effect should, therefore, be restricted to a conceptual orienting task, and it should be reduced in the SPT condition.

To test these hypotheses, we ran the following experiments. The basic factors were always the same: type of encoding (SPT and VT), orienting task (verbal surface and conceptual tasks), and congruity (matching and non- 
matching assertions). Therefore, we will begin with the common part of the procedure and then present the individual experiments.

\section{GENERAL METHOD}

We always utilized one conceptual and one nonconceptual orienting task, except for Experiment 2, in which two nonconceptual orienting tasks were used. For each item, the subjects first read the orienting task, which was an assertion about a conceptual or verbal surface feature of the following item, and then the item was presented for which the assertion had to be verified. In the VT condition, the orienting tasks were given without any additional instructions. In the SPT condition, the subjects were provided with the additional instruction to perform each action. The orienting tasks were completely crossed with the encoding condition. An unexpected free-recall test was given after presentation of the items. In some of the experiments, the subjects had multiple learning testing sequences. In this case, we informed them in advance about the freerecall test that would follow. In those experiments, however, we asked our subjects only to perform the orienting tasks, because we were interested in the influence of this type of processing on memory.

\section{Material}

We used action phrases as learning material. Each phrase denoted a manipulation of an object. All the phrases were simple verb-object phrases in German - for example, die Karten mischen (shuffle the playing cards), die Flasche aufschrauben (unscrew the lid of the bottle), die Briefmarke aufkleben (apply on the postage-stamp). A larger set of examples for SPTs has been provided by Cohen (1981) and by Zimmer and Engelkamp (1985).

To manipulate the levels of processing, different types of assertions were constructed for each phrase and were used in the orienting tasks. As verbal surface tasks, we used either a letter-triplet matching task or a letter-counting task. For conceptual orienting tasks, the subjects had to assess the adequacy of a given context. With all types of orienting tasks, a different question was used for each phrase, and therefore, the distinction provided by the number of possible categories was comparable for the three orienting tasks (cf. Intraub \& Nicklos, 1985).

For the triplet task, a triplet of letters from each phrase was selected. This triplet was taken from the noun or the verb of the phrase an equal number of times, and over items, the triplet was taken as frequently from the initial, middle, or end positions of the words The subjects had to assess whether the triplet was a part of the phrase (e.g., efm for die Briefmarke aufkleben). In the letter-counting task, the subjects had to decide whether a letter occurred at a prespecified frequency in the phrase (e.g., the letter $e$ five times). To set up the conceptual task, a possible context for each action was searched for. Examples of these contexts for the phrases given above were in the pub, on a picnic, and in the post office, respectively.

From this material, different study lists were constructed. In each list, an equal amount of the material was assigned to each of the orienting tasks. With three orienting tasks, for example, one third of the items were assigned to the letter, one third to the triplet, and one third to the conceptual task. Half of the items were matching and were combined with correct assertions (the correct answer would be yes), whereas the other half of the items were recombined with the assertions in order to construct nonmatching pairs (the correct answer would be no). Across subjects, the assignment of items to conditions (orienting tasks) and congruity (matching or nonmatching) was counterbalanced.

\section{Procedure}

The subjects were told that we were interested in the time a person needs to verify assertions about different aspects of stimuli. For this purpose, we presented them with a series of phrases denoting actions, and we asked a question about each phrase. The question concerned, for example, the phrase itself or a possible context of the denoted action. For each type, examples were given to items not used in the study lists. The subjects were required to assess the correctness of the assertion by pushing one of two buttons of the computer keyboard (right shift key for yes, left shift key for no).

Questions and action phrases were presented on a computer screen by the Experimental Run Time System (ERTS, Berisoft). The presentation conditions in a trial were as follows. Each trial was introduced by a warning signal (a beep), and the to-be-verified assertion followed $500 \mathrm{msec}$ later. The question was presented for $3 \mathrm{sec}$ in the middle of the screen, and after an interstimulus interval of $1,000 \mathrm{msec}$, it was followed by the target phrase. The target phrase was seen for a maximum time of $6 \mathrm{sec}$, and it disappeared when the subject answered. One sec later, the next trial started. The subjects practiced the procedure with a short practice list. The item presentation was self-paced, to avoid a surplus of processing of the item during the presentation time remaining after the answer to the orienting task had already been given. From other studies in our lab, we know that it takes approximately the same length of time to answer the surface tasks as to answer the conceptual tasks. Furthermore, in this study there was no correlation between time of decision and memory performance, so we were able to ignore this aspect.

The subjects in the eracting group were told that we wanted to find out how enacting influences performance. They were instructed to pretend to perform the actions with fictitious objects as clearly as possible - that is, no real objects were handed to them.

When they were finished, the subjects were given instructions for free recall. In the incidental learning conditions, none of the subjects said, when asked at the end of the experiment, that they had expected a memory test while working on the orienting tasks. In freerecall tests, the subjects were to write down all remembered items. In Experiments 2 and 3, in which the subjects studied multiple short lists, with a free-recall test after each list (the procedure used by Nilsson and Craik, 1990), the subjects were informed about the freerecall test in advance. As the data will show, knowledge of the following free recall test did not influence the results.

\section{EXPERIMENT 1}

In Experiment 1, we required our subjects to work on a 60 -item study list in an incidental procedure. Half of the subjects had VT and half SPT instructions. We used two orienting tasks. The first task oriented the subjects to the verbal surface of the phrases (the letter-triplet task), and the second task oriented the subjects to the meaning of the phrases. In the latter case, the subjects had to assess whether a given context was adequate for the action.

\section{Method}

Forty Saarland University students from departments other than psychology participated as volunteers in the experiment. They were paid for their participation.

The experiment was a three-factorial design, with the factors encoding condition (VT/SPT), orienting task (conceptual/verbal surface), and congruity (matching/nonmatching). Encoding was varied between subjects; the other two factors were varied within subjects.

\section{Results and Discussion}

The proportion of correctly recalled items is shown in Table 1 . A $2 \times 2 \times 2$ analysis of variance (ANOVA) was carried out with the factors encoding condition, orienting task, and congruity, respectively. All the effects re- 
Table 1

Mean Proportion Recalled $(M)$ and Standard Errors $(S E)$, Dependent on Encoding Condition, Congruity, and Orienting Task in Experiment 1 (60 Items)

\begin{tabular}{|c|c|c|c|c|c|}
\hline \multirow[b]{3}{*}{ Encoding condition } & \multirow[b]{3}{*}{ Congruity } & \multicolumn{4}{|c|}{ Orienting Task } \\
\hline & & \multicolumn{2}{|c|}{ Concept } & \multicolumn{2}{|c|}{ Triplet } \\
\hline & & $M$ & $S E$ & $\bar{M}$ & $S E$ \\
\hline \multirow[t]{3}{*}{ Verbal task } & Matching & .35 & .036 & .07 & .015 \\
\hline & Nonmatching & .18 & .025 & .02 & .009 \\
\hline & Mean & .25 & & .05 & \\
\hline \multirow[t]{3}{*}{ Subject-performed task } & Matching & .40 & .024 & .25 & .028 \\
\hline & Nonmatching & .32 & .028 & .19 & .037 \\
\hline & Mean & .33 & & .21 & \\
\hline
\end{tabular}

Note-Matching refers to trials with correct assertions; nonmatching refers to trials with wrong assertions.

ported as significant in this article had $p$ values of less than .05 .

We first looked at the influence of the encoding conditions and the orienting tasks. The subjects in the SPT condition (.29) reported more items than those in the VT condition $\left[.15 ; F(1,38)=26.90, M S_{\mathrm{e}}=0.07\right]$. Furthermore, recall performances for items processed under surface orienting tasks $(.13)$ were lower than for those processed conceptually $\left[.31 ; F(1,38)=57.27, M S_{\mathrm{e}}=0.02\right]$. However, the interaction between encoding condition and orienting task was not quite significant $[F(1,38)=$ $\left.3.04, M S_{\mathrm{e}}=0.02, p=.08\right]$. With both encoding conditions, we observed levels-of-processing effects, as post hoc tests revealed, and the effect was higher for the VT (.22) than for the SPT condition (.14), but this deviation was not significant. Furthermore, with a surface orienting task, a strong SPT advantage was found, which was much smaller with a conceptual orienting task, and within this orienting task the encoding effect was no longer significant for matching pairs.

Congruity also influenced the memory performances. Items that were paired with correct assertions were reported more often $(.27)$ than those paired with wrong assertions $\left[.18 ; F(1,38)=29.99, M S_{\mathrm{e}}=0.01\right]$. In addition, this effect was modulated by the type of orienting task. The interaction between orienting task and congruity was also significant $\left[F(1,38)=9.45, M S_{\mathrm{e}}=0.01\right]$. In the triplet task, memory performances for matching (.16) and nonmatching trials (.11) did not significantly differ from each other, whereas in the conceptual condition, matching trials $(.37)$ were recalled better than nonmatching trials $(.24)$.

The triple interaction was not significant, but because we only predicted a two-fold interaction between type of encoding and congruity with a conceptual orienting task, we analyzed the data separately for this condition. If we analyzed only the conceptual condition, the interaction between type of encoding and congruity was significant $\left[F(1,38)=4.87, M S_{\mathrm{e}}=0.01\right]$. Whereas the difference between matching and nonmatching trials was .17 in the VT condition, it was only .08 in the SPT condition. In contrast, with a surface orienting task, no significant dif- ferences were observed that were dependent on congruity $(F<1)$.

As was predicted, in the enactment condition, freerecall performance suffered when processing was directed to the verbal surface during encoding, but recall was still high in SPTs with such a surface encoding task. This effect was expected because in SPTs, even in the surface conditions, subjects should process the meaning of the items in order to perform the actions. As was expected, recall in VTs was nearly as good as recall in SPTs with a conceptual orienting task. Nevertheless, in SPTs, a conceptual encoding condition was also better than the surface encoding condition. However, contrary to our expectations, although the levels-of-processing effect-the influence of the orienting task - was numerically smaller in the SPT encoding condition than in the VT encoding condition, this difference was not significant. A closer look at Table 1 shows that this finding might be due to the very low recall performance in the triplet task with the VT condition. It seems that the list was too difficult when there was a nonconceptual instruction in the VT condition.

When one compares the results of Experiment 1 with the findings of Nilsson and Craik (1990) and of Zimmer (1992), they are not fully consistent with either. Zimmer observed clear effects of the orienting tasks in the SPT and in the VT conditions, and these effects were of similar size in both encoding conditions. In contrast, Nilsson and Craik observed an interaction between the kind of processing and the type of encoding, and in their study, the processing effect was nearly absent in the SPT condition. In Experiment 1, we got clear levels-of-processing effects in both encoding conditions, as Zimmer had observed, but the effect was numerically smaller in the SPT condition than in the VT condition, as Nilsson and Craik had observed. A possible cause for these differences might be list length. Whereas Zimmer used a long list, as we have, Nilsson and Craik used short lists of 12 items. Moreover, their subjects did not study one list, but several lists, with a free-recall test after each list.

\section{EXPERIMENT 2}

The main goal of Experiment 2 was, therefore, to explore whether the levels-of-processing effect is modulated by list length. The subjects in Experiment 2 studied either one long list or three short lists, with a free-recall test after each list. The long list was set at 72 items, and the short ones were set at 12 items, as in Nilsson and Craik (1990). By doing so, the same items were studied under the same orienting tasks-in long lists, as in Experiment 1, and in short lists, as in the Nilsson and Craik experiment. In addition, we used letter counting as a second surface task. This task was used by Nilsson and Craik, and, in principle, it is possible that the different surface tasks show different memory effects. As a conceptual orienting task, we used again the context task, which was also used by Nilsson and Craik. 


\section{Method}

One hundred and twenty paid volunteers participated in Experiment 2 to enhance the power of the study. None of the subjects had taken part in Experiment 1. Three orienting tasks were used. A context-matching task was used for conceptual encoding, and lettertriplet and letter-counting tasks were used for verbal surface encoding. List length and encoding condition were varied between subjects; the orienting task was varied within subjects.

\section{Results and Discussion}

The proportion of correct responses in free-recall tests is reported in Table 2. A four-way ANOVA, with the factors list length (2), encoding condition (2), congruity (2), and levels-of-processing (3), was run. One subject, from the verbal encoding condition with short lists, was excluded from the analysis because her data were incomplete.

Once again, recall in the two verbal surface conditions (letter, .23; triplet, .24) was worse than that in the conceptual condition $\left[.42 ; F(2,230)=109.14, M S_{\mathrm{e}}=0.04\right]$. This time, the level-of-processing effect interacted with the type of encoding $\left[F(2,230)=24.27, M S_{\mathrm{e}}=0.03\right]$. Orienting subjects during encoding to the verbal surface impaired recall under the VT condition $(.27)$ more than under the SPT condition (.11), which was still significant, however. This is the interaction between type of encoding and levels of processing that was expected. Overall, SPT recall $(.36)$ was better than VT recall $[.22 ; F(1,115)=$ 91.63, $\left.M S_{\mathrm{e}}=0.04\right]$, and recall in the SPT condition was remarkably good even with surface orienting tasks. As in Experiment 1 with a conceptual orienting task, the SPT effect was no longer observed (VT, .41; SPT, .43).

Furthermore, the subjects recalled more items from matching trials than from nonmatching trials, and again, this effect was mainly due to the conceptual orienting task, as the two-way interaction between the congruity and the type of orienting task showed $[F(2,230)=10.68$,
$\left.M S_{\mathrm{e}}=0.02\right]$. The difference between matching and nonmatching trials was 0 for the letter-counting, .07 for the triplet, and .12 for the conceptual tasks. In this experiment, the triple interaction between the encoding condition, levels of processing, and congruity was also significant $\left[F(2,230)=5.55, M S_{\mathrm{e}}=0.02\right]$. With surface orienting tasks, the congruity effects did not significantly interact with the type of encoding, whereas in the conceptual encoding condition, the congruity effect was smaller in the SPT condition (.08) than in the VT condition [.17; $\left.F(1,115)=4.55, M S_{\mathrm{e}}=0.02\right]$.

The fourth factor in this experiment was list length. Of course, short lists (.42) were better recalled than long lists $\left[.17 ; F(1,115)=293.42, M S_{\mathrm{e}}=0.04\right]$. In addition, type of encoding and type of orienting task interacted with list length $\left[F(2,230)=4.17, M S_{\mathrm{e}}=0.03\right]$. As was expected, the levels-of-processing effect was influenced by list length. In separate analyses for the two encoding conditions, list length and orienting task interacted in the VT condition, but not in the SPT condition. As compared with the conceptual condition, in the VT condition, a verbal surface encoding reduced recall by .34 in short lists and by .22 in long lists, whereas in the SPT condition, the reduction was 10 for both lists. Thus, the expected interaction between type of encoding and level of processing could be more clearly observed with short than with long lists. This is due to the fact that the maximal and minimal recall performances limit the maximally possible levelsof-processing effect, and this range is higher for short than for long lists.

The findings of Experiment 2 clearly show the expected interaction between type of encoding and levels of processing. Although a clear levels-of-processing effect can be observed in the VT and SPT conditions, the effect is reduced in the SPT condition. Whereas type of surface

Table 2

Mean Proportion Recalled $(M)$ and Standard Errors $(S E)$, Dependent on Encoding Condition, Congruity, Orienting Task, and List Length in Experiment 2 (72/12 Items)

\begin{tabular}{|c|c|c|c|c|c|c|c|}
\hline \multirow[b]{3}{*}{ Encoding condition } & \multirow[b]{3}{*}{ Congruity } & \multicolumn{6}{|c|}{ Orienting task } \\
\hline & & \multicolumn{2}{|c|}{ Concept } & \multicolumn{2}{|c|}{ Triplet } & \multicolumn{2}{|c|}{ Letter } \\
\hline & & $M$ & $S E$ & $M$ & $S E$ & $M$ & $S E$ \\
\hline \multicolumn{8}{|c|}{ Short Lists } \\
\hline \multirow[t]{3}{*}{ Verbal task } & Matching & .64 & .035 & .31 & .046 & .21 & .039 \\
\hline & Nonmatching & .45 & .035 & .09 & .037 & .23 & .037 \\
\hline & Mean & .55 & & .20 & & .22 & \\
\hline \multirow[t]{3}{*}{ Subject-performed task } & Matching & .62 & .042 & .52 & .044 & .48 & .040 \\
\hline & Nonmatching & .53 & .038 & .46 & .038 & .46 & .037 \\
\hline & Mean & .58 & & .49 & & .47 & \\
\hline \multicolumn{8}{|c|}{ Long Lists } \\
\hline \multirow[t]{3}{*}{ Verbal tasks } & Matching & .34 & .029 & .08 & .016 & .02 & .005 \\
\hline & Nonmatching & .19 & .024 & .05 & .015 & .04 & .011 \\
\hline & Mean & .26 & & .07 & & .03 & \\
\hline \multirow[t]{3}{*}{ Subject-performed tasks } & Matching & .32 & .026 & .16 & .015 & .19 & .011 \\
\hline & Nonmatching & .24 & .020 & .20 & .027 & .16 & .022 \\
\hline & Mean & .28 & & .18 & & .18 & \\
\hline
\end{tabular}

Note-Matching refers to trials with correct assertions; nonmatching refers to trials with wrong assertions. 
orienting did not change the outcome, list length influenced the size of the levels-of-processing effect in the VT condition. We will discuss this finding in more detail in the General Discussion section.

The interaction between type of encoding and congruity with a conceptual orienting task could be replicated. In the conceptual encoding condition, the congruity effect was smaller in the SPT condition than in the VT condition.

\section{EXPERIMENT 3}

Despite the consistencies of the reported experimental results, there is still the disagreement that, unlike Nilsson and Craik (1990), we observed a clear-cut levelsof-processing effect also in the SPT condition for short lists. A closer look at Nilsson and Craik's study shows that they varied the orienting tasks between lists; we varied them within lists. If output interference had an effect on recall, items that were more easily retrieved-that is, those that were conceptually encoded-might have been recalled at the expense of weaker items-that is, those that were encoded with a surface orienting task. As a consequence, output interference would impair recall of surface items more than that of conceptually encoded items. This might be an additional factor that enhanced the levels-of-processing effect, and this effect is even stronger if the recall level is high, as in the SPT condition. In other words, if we could reduce this tradeoff, the size of the levels-of-processing effect would be further reduced, and in the SPT condition, this further reduction might then let levels-of-processing effects completely disappear. We tested this in Experiment 3, in which the whole list was processed under homogenous encoding conditions. All the items on a list were encoded under a conceptual or a surface task.

\section{Method}

Thirty-two paid students participated in this experiment. These subjects had not participated in one of the other experiments. Half of the subjects studied under VT conditions, and half under SPT instructions. The levels of processing were varied within subjects, but between lists. Because the type of surface task did not have any effect in Experiment 2, we utilized only one conceptual and one surface task: the conceptual and the triplet tasks, respectively. Each subject learned eight lists of 12 items. Four lists were studied under surface tasks, and four under conceptual orienting tasks, with a free-recall test after each list presentation. The sequence of conditions was balanced.

\section{Results and Discussion}

In Table 3, the proportion of correctly recalled items is reported. We calculated a three-factorial ANOVA, with the factors encoding condition (2), orienting task (2), and congruity (2).

In this experiment, we observed again a clear effect of the type of orienting task. With conceptual encoding, the subjects recalled more items (.46) than with a surface orienting task $\left[.34 ; F(1,30)=56.58, M S_{\mathrm{e}}=0.01\right]$. This
Table 3

Mean Proportion Recalled $(M)$ and Standard Errors $(S E)$, Dependent on Encoding Condition, Congruity, and Orienting Task in Experiment 3 (12 Items, Orienting Tasks Blocked Within Lists)

\begin{tabular}{|c|c|c|c|c|c|}
\hline \multirow[b]{3}{*}{ Encoding Condition } & \multirow[b]{3}{*}{ Congruity } & \multicolumn{4}{|c|}{ Orienting Task } \\
\hline & & \multicolumn{2}{|c|}{ Concept } & \multicolumn{2}{|c|}{ Triplet } \\
\hline & & $M$ & $S E$ & $M$ & $S E$ \\
\hline \multirow[t]{3}{*}{ Verbal task } & Matching & .50 & .035 & .30 & .038 \\
\hline & Nonmatching & .39 & .030 & .25 & .025 \\
\hline & Mean & .45 & & .27 & \\
\hline \multirow[t]{3}{*}{ Subject-performed task } & Matching & .52 & .035 & .44 & .028 \\
\hline & Nonmatching & .43 & .033 & .36 & .035 \\
\hline & Mean & .48 & & .40 & \\
\hline
\end{tabular}

Note-Matching refers to trials with correct assertions; nonmatching refers to trials with wrong assertions.

time, encoding condition and orienting task again interacted $\left[F(1,30)=8.54, M S_{\mathrm{e}}=0.01\right]$. However, although the levels-of-processing effect was smaller in the SPT condition (.08) than in the VT condition (.18), the simple main effects for the kind of processing were significant in both encoding conditions. Again, under conceptual encoding, no differences between the encoding conditions were observed, but clear differences were obtained in the surface conditions. Furthermore, matching trials were recalled better than nonmatching trials $\left[F(1,30)=21.91, M S_{\mathrm{e}}=0.01\right]$, which effect was more pronounced with the conceptual orienting task (.11) than with the triplet task $(.06)$.

In this experiment, in which we used the same encoding conditions as did Nilsson and Craik (1990), the results we obtained were comparable with theirs. In their experiment, the levels-of-processing effect was .22 in the VT condition and .07 in the SPT condition (for young adults); we observed, in this experiment, effects of 18 and .08 . However, the levels-of-processing effect was clearly significant in the SPT condition as well, although we presented homogenous lists. Contrary to our expectations, the recall performances in Experiments 2 and 3 were very similar, which indicates that output interference does not strongly contribute to the levels-of-processing effects in these experiments.

\section{GENERAL DISCUSSION}

This series of experiments established a number of reliable results. First, in all the experiments, free recall in SPTs showed levels-of-processing effects, and these processing effects were smaller after SPT encoding than after VT encoding, although they were always significant. Second, with SPT encoding, a substantial recall was observed even with surface encoding, and this was also the case for long lists, under which condition the subjects in the VT group recalled nearly nothing. As a consequence, there was a huge SPT effect with shallow orienting tasks, but this effect was strongly reduced with a conceptual orienting task. Third, congruity influenced free recall 
Table 4

Mean Proportion Recalled and Effect Size, Dependent on Encoding Condition, Orienting Task, and Experiment

\begin{tabular}{|c|c|c|c|c|c|c|c|c|}
\hline \multirow[b]{3}{*}{ Encoding Condition } & \multirow[b]{3}{*}{ Orienting Task } & \multicolumn{7}{|c|}{ Experiment } \\
\hline & & $\mathrm{Zi}$. & 1 & 2 & 2 & 3 & $\mathrm{~N} \& \mathrm{C}, \mathrm{Y}$ & $\mathrm{N} \& \mathrm{C}, \mathrm{E}$ \\
\hline & & $(n=48)$ & $\overline{(n=60)}$ & $\overline{(n=72)}$ & $\overline{(n=12)}$ & $\overline{(n=12)}$ & $\overline{(n=12)}$ & $\overline{(n=12)}$ \\
\hline \multirow[t]{4}{*}{ Verbal } & Conceptual task & .16 & .26 & .27 & .55 & .45 & .57 & .27 \\
\hline & Verbal surface task & .02 & .04 & .05 & .21 & .27 & .39 & .13 \\
\hline & Conceptual advantage & .14 & .22 & .22 & .34 & .18 & .18 & .14 \\
\hline & Effect size $\left(\omega^{2}\right)$ & .19 & .33 & .34 & .33 & .15 & - & - \\
\hline \multirow[t]{4}{*}{ Subject-performed } & Conceptual task & .26 & .36 & .28 & .58 & .48 & .61 & .31 \\
\hline & Verbal surface task & .16 & .22 & .18 & .48 & .40 & .54 & .29 \\
\hline & Conceptual advantage & .10 & .14 & .10 & .10 & .08 & .07 & .02 \\
\hline & Effect size $\left(\omega^{2}\right)$ & .03 & .11 & .10 & .04 & .05 & - & - \\
\hline
\end{tabular}

Note $-n=$ number of items in the study list. Zi., data from Zimmer (1992); 1 to 3, Experiments 1 to 3 of this report; N\&C, estimated data from Figure 3 of Nilsson \& Craik (1990); Y, young adults; E, elderly adults; -, data not available.

consistently only with conceptual encoding. With the conceptual task, items from matching trials were recalled better than those from nonmatching trials. This congruity effect was more pronounced in the VT condition than in the SPT condition. Finally, the levels-of-processing effect and its interaction with the type of encoding were modulated by list length.

Levels-of-processing effects are usually explained by the assumption that, with a conceptual orienting task (e.g., asking for the context of an action), subjects have to make available the meaning of the item and have to retrieve additional information from long-term memory. On the one hand, this leads to a distinct representation of the item, and on the other hand, it integrates the item into preexisting knowledge. In this way, the context task provides subjects with information suitable for later retrieval, which enables high recall performances. This effect is higher for congruent tasks than for incongruent ones, because congruent items are better integrated than incongruent ones. In contrast, questions about verbal surface information induce linguistic information. This information does not facilitate item recovery at the time of testing, and because surface information does not integrate items efficiently into memory, congruity is not very important. As a consequence, recall under the verbal surface condition is usually low.

In VTs, the information provided by the orienting task is the only information present, and surface encoding therefore leads to memory performance that is much lower than that after conceptual encoding. This is different in SPTs. In SPTs, conceptual encoding takes place even with surface orienting tasks, because the actions are to be performed. Therefore, the SPT recall is still substantial even after a surface orienting task. However, conceptual processing is restricted to the action-relevant information, and this connects an item less to memory than does, for example, a context task. As a consequence, recall is still worse with a verbal surface task than with a conceptual task even in an SPT, because less integrated items are not as available as highly integrated items.

Before closing, we will return to the size of the levelsof-processing effect in more detail. Table 4 gives an over- view of the levels-of-processing effects that were observed in free-recall tests in the three present experiments and in the relevant experiments reported in the literature.

As one can see, in all the experiments, except for the elderly group of the Nilsson and Craik (1990) study, reliable levels-of-processing effects were observed under SPT encoding conditions. However, the processing effect was much smaller with SPTs than with VTs. This conclusion is supported by the estimations of the effect size of the levels-of-processing factor. We calculated omega squared (Dodd \& Schultz, 1973) for SPT and VT free recall in Experiments 1-3 separately for short and long lists. The resulting data are also given in Table 4 . The picture is clear-cut. The processing effect is generally large for VTs, and it is of small size for SPTs. In addition, the advantage of a conceptual encoding varied over the experiments, and in VTs more than in SPTs. This variation is probably caused by the boundaries of the free-recall performances. The lowest possible recall performance (the zero level) is quickly reached in a VT if the length of the list is increased. Similarly, the highest recall level is limited-for example, by list length as well as by the efficiency of the conceptual task. These two factors limit the levels-of-processing effect, and the size of the effect is, therefore, variable even within identical encoding tasks, as in VTs and in SPTs. Such accidental influences had most likely caused the additivity of levels-of-processing effects and the type of encoding effects that Zimmer (1992) had observed. In general, levels-of-processing effects also occur in SPTs, as he had concluded, but they are substantially smaller than those in VTs.

\section{REFERENCES}

COHEN, R. L. (1981). On the generality of some memory laws. Scandinavian Journal of Psychology, 22, 267-281.

COHEN, R. L. (1983). The effect of encoding variables on the free recall of words and action events. Memory \& Cognition, 11, 575-582.

COHEN, R. L. (1989). Memory for action events: The power of enactment. Educational Psychological Review, 1, 57-80.

Craik, F. I. M., \& LockharT, R. S. (1972). Levels of processing: A framework for memory research. Journal of Verbal Learning \& Verbal Behavior, 11, 671-684.

Craik, F. I. M., \& Tulving, E. (1975). Depth of processing and the re- 
tention of words in episodic memory. Journal of Experimental Psychology: General, 104, 268-294.

DodD, D. H., \& Schultz, R. F. (1973). Computational procedures for estimating magnitude of effect for some analyses of variance designs. Psychological Bulletin, 79, 391-395.

Engelkamp, J. (1991). Memory of action events: Some implications for memory theory and for imagery. In C. Cornoldi \& M. A. McDaniel (Eds.), Imagery and cognition (pp. 183-219). New York: SpringerVerlag.

Engelkamp, J. (1998). Memory for actions. Hove, U.K.: Psychology Press.

Engelkamp, J., Mohr, G., \& Zimmer, H. D. (1991). Pair-relational encoding of performed nouns and verbs. Psychological Research, 53, 232-239.

Engelkamp, J., \& Zimmer, H. D. (1994). The human memory: A multimodal approach. Seattle: Hogrefe.

HANLEY, J. R., \& MoRRIS, P. (1987). The effects of amount of processing on recall and recognition. Quarterly Journal of Experimental Psychology, 39A, 431-449.

HelstruP, T. (1987). One, two, or three memories? A problem-solving approach to memory for performed acts. Acta Psychologica, 66, $37-68$

Hunt, R. R., \& Einstein, G. O. (1981). Relational and item-specific information in memory. Journal of Verbal Learning \& Verbal Behavior, 20, 497-514.

INTRAUB, H., \& NickLOS, S. (1985). Levels of processing and picture memory: The physical superiority effect. Journal of Experimental Psychology: Learning, Memory, \& Cognition, 11, 284-298.

JaCOBY, L. L., \& CraIK, F. I. M. (1979). Effects of elaboration of processing at encoding and retrieval: Trace distinctiveness and recovery of initial context. In L. S. Cermak \& F. I. M. Craik (Eds.), Levels of processing in human memory (pp. 1-22). Hillsdale, NJ: Eribaum.

Johnson-Laird, P. N., GibBs, G., \& DE Mowbray, J. (1978). Meaning, amount of processing, and memory for words. Memory \& Cognition, 6, 372-375.

Koriat, A., \& MELKMAN, R. (1987). Depth of processing and memory organization. Psychological Research, 49, 173-181.

LiChTY, W., Bressie, S., \& KRELL, R. (1988). When a fork is not a fork:
Recall of performed activities as a function of age, generation, and bizarreness. In M. M. Gruneberg, P. E. Morris, \& R. N. Sykes (Eds.), Practical aspects of memory: Current research and issues (Vol. 2, pp. 506-511). Toronto: Wiley.

Lockhart, R. S., \& Craik, F. I. M. (1990). Levels of processing: A retrospective commentary on a framework of memory research. Canadian Journal of Psychology, 44, 87-112.

McDaniel, M. A., Einstein, G. O., Dunay, P. K., \& Cobb, R. E. (1986). Encoding difficulty and memory: Toward a unifying theory. Journal of Memory \& Language, 25, 645-656.

NeLSON, D. (1979). Remembering pictures and words: Appearance, significance, and name. In L. S. Cermak \& F. I. M. Craik (Eds.), Levels of processing in human memory (pp. 45-78). Hillsdale, $\mathrm{NJ}$ : Erlbaum.

NiLsSON, L. G., \& B ÄCKMAN, L. (1989). Implicit memory and the enactment of verbal instructions. In S. Lewandowsky, J. C. Dunn, \& K. Kirsner (Eds.), Implicit memory: Theoretical issues (pp. 173-183). Hillsdale, NJ: Erlbaum.

Nilsson, L. G., \& COHEN, R. L. (1988). Enrichment and generation in the recall of enacted and non-enacted instructions. In M. M. Gruneberg, P. E. Morris, \& R. N. Sykes (Eds.), Practical aspects of memory: Current research and issues (pp. 427-432). Chichester, U.K.: Wiley.

Nilsson, L. G., \& Craik, F. I. M. (1990). Additive and interactive effects in memory for subject-performed tasks. European Journal of Cognitive Psychology, 2, 305-324.

Nilsson, L. G., Nyberg, L., Kormi-Nouri, R., \& Rönnlund, M. (1994). Dissociative effects of elaboration on memory of enacted and non-enacted events: A case of a negative effect. Scandinavian Journal of Psychology, 35, 225-231.

ZIMMER, H. D. (1992, September). No LOP-effects with subject performed tasks? They are there. Paper presented at the 5th conference of the European Society of Cognitive Psychology, Paris.

Zimmer, H. D., \& Engelkamp, J. (1985). An attempt to distinguish between kinematic and motor memory components. Acta Psychologica, 58, 81-106.

(Manuscript received March 5, 1998; revision accepted for publication September 15, 1998.) 